\title{
Über die Verflüssigung des Sauerstoffes und die Erstarrung des Schwefelkohlenstoffes und Alkohols. ${ }^{1}$
}

\author{
Von Prof. Dr. Sigm. v. Wroblewski und Prof. Dr. K. Olszewski \\ an der k. k. Universitüt in Krakau.
}

(Vorgelegt in der Sitzung am 12. April 1883.)

Die Resultate, zu welchen Cailletet und Raoul Pictet in ihren schönen Arbeiten tiber die Verflüssigung der Gase gekommen sind, erlaubten $z \mathfrak{u}$ hoffen, dass die Zeit unweit ist, wo man im Stande sein wird, den fliissigen Sauerstoff ebenso leicht in einer Glasröhre zu beobachten, wie dies gegenwärtig mit der flüssigen Kohlensäure der Fall ist. Die einzige Bedingung dazu war die Erreichung einer hinreichend niedrigen Temperatur. In einer vor einem Jahre publicirten Abhandlung ${ }^{2}$ hat Cailletet das flissige Äthylen als ein Mittel zur Erreichung einer sehr niedrigen Temperatur empfohlen. Das verflüssigte Gas siedet nämlich unter d em atmosphärischen Drucke bei $-105^{\circ} \mathrm{C}$, wenn man die Temperatur mit einem Schwefelkohlenstoff-Thermometer misst Cailletet selbst comprimirte den Sauerstoff in einer sehr engen Glasröhre, die in dieser Flüssigkeit auf $-105^{\circ} \mathrm{C}$. abgekühlt war. Im Augenblicke der Expansion sah er "une ébullition tumultueuse qui persiste pendant un temps appréciable et ressemble à la projection d'un liquide dans la partie du tube refroidi. Cette ébullition se forme à une certaine distance du fond du tube. Je n'ai pu reconnaître - setzt er hinzu - si ce liquide préexiste ou s'il se forme au moment de la détente, car je n'ai pu voir encore le plan de séparation du gaz et du liquide."

Da einer von uns $^{3}$ neulich einen neuen Apparat für hohe Drucke construirt hat, mit welchem man verhältnissmässig grosse Gasmengen dem Drucke von einem paar Hundert Atmosphären

1 Ans dem Auzeiger der k. Akademie der Wissenschaften vom 12. April 1883. Nr. IX.

2 Comptes Rendus, t. 94, p. 1224-1226.

3 S. v. Wroblewski. 
338 Wroblewski u. Olszewski. Über die Verflïssigung etc.

auszusetzen im Stande ist, so wollten wir uns dieses Apparates bedienend die Temperaturen im Augenblicke der Expansion studiren. Diese Versuche führten uns bald zur Entdeckung einer Temperatur, bei welcher Schwefelkohlenstoff und Alkohol erstarren und Sauerstoff sich mit grosser Leichtigkeit vollständig verflüssigt. Diese Temperatur erreicht man, wenn mandas fl üsige Äthylen im Vacuum sieden lässt. Die Siedetemperatur hängt in solchem Falle von der Gutte des erhaltenen Vacuums ab. Bei der Verdünnung, welche uns zu erreichen bis jetzt möglich gewesen ist, steigt die Temperatur bis auf $-136^{\circ} \mathrm{C}$. herunter. Diese Temperatur, sowie alle anderen Temperaturen haben wir mit dem Wasserstoff-Thermometer gemessen.

Die kritische Temperatur des Sauerstoffes ist niedriger als diejenige, bei welcher das flüssige Äthylen unter dem Drucke von einer Atmosphäre siedet. Die letztere ist nicht $-105^{\circ} \mathrm{C}$, wie man es bis jetzt angenommen hat, sondern liegt zwischen -102 und $-103^{\circ} \mathrm{C}$, wie wir es mit unseren Thermometern gefunden haben.

Aus einer Reihe von Beobachtungen, die wir am 9. April d. J. ausgeftihrt haben, entnehmen wir als ein Beispiel folgende Zahlen, um einen Begriff von der Sachlage zu geben.

\begin{tabular}{cc} 
Temperatur & $\begin{array}{c}\text { Druck in Atmosphären, } \\
\text { unter welchem der Sauer- } \\
\text { stoff sich zu verflissigen } \\
\text { angefangen hat }\end{array}$ \\
\hline$-131.6^{\circ} \mathrm{C}$. & 26.5 \\
$-133.4 "$ & 24.8 \\
$-135.8 \%$ & 22.5
\end{tabular}

Wir behalten uns die Mittheilung der definitiven Zahlen vor.

Der flüssige Sauerstoff ist farblos und durchsichtig wie die flüssige Kohlensäure. Er ist sehr beweglich und bildet einen schönen Meniscus.

Was den Schwefelkohlenstoff anbetrifft, so erstarrt er bei etwa $-116^{\circ} \mathrm{C}$. und wird flüssig bei etwa $-110^{\circ} \mathrm{C}$. Der absolute Alkohol wird bei $-129^{\circ} \mathrm{C}$. zähflüssig wie öl und erstarrt zu ainer festen Masse bei etwa $-130 \cdot 5^{\circ} \mathrm{C}$. Auch hier behalten wir uns die Mittheilung der definitiven Zahlen vor. 